Revue d'histoire de l'enfance « irrégulière »

Le Temps de l'histoire

9 | 2007

Violences et jeunesse

\title{
Jean-Claude Vimont [dir.], « Jeunes, déviances et identités - XVIIIème-XXème siècle »
}

Jean-Jacques Yvorel

\section{OpenEdition}

1 Journals

Édition électronique

URL : http://journals.openedition.org/rhei/2623

DOI : 10.4000/rhei.2623

ISBN : 978-2-7535-1648-9

ISSN : $1777-540 \mathrm{X}$

Éditeur

Presses universitaires de Rennes

Édition imprimée

Date de publication : 15 novembre 2007

Pagination : 265-266

ISSN : 1287-2431

Référence électronique

Jean-Jacques Yvorel, « Jean-Claude Vimont [dir.], « Jeunes, déviances et identités - XVIIlème-XXème siècle » », Revue d'histoire de l'enfance « irrégulière » [En ligne], 9 | 2007, mis en ligne le 23 janvier 2009, consulté le 04 décembre 2020. URL : http://journals.openedition.org/rhei/2623 ; DOI : https://doi.org/ 10.4000/rhei.2623 
Jean-Claude Vimont, [dir.]

" Jeunes, déviances et identités - XVIIIème-XXème siècle - "

Cahiers du GRHis, ${ }^{\circ} 15$,

Publication des universités de Rouen et du Havre, 2005, 157 p.

L'université de Rouen, sous l'impulsion de Yannick Marec et surtout de Jean-Claude Vimont, contribue largement au développement de l'histoire de l'enfance "irrégulière ". Cette livraison des Cahiers du GRHis (groupe de recherche en histoire) témoigne de cette activité. Jean-Claude Vimont a rassemblé neuf articles où la notion d'identité sert de fils conducteur. Les textes de chercheurs confirmés (Jean-Claude Farcy, Benoît Garnot, Jean-Claude Vimont) voisinent avec les travaux de jeunes doctorants ou d'étudiants de master. Un vrai travail éditorial donne à l'ensemble une rare cohésion s'agissant d'une publication collective.

Benoît Garnot fait le point sur « la délinquance masculine dans la France du XVIIIème siècle ». Pour réaliser sa synthèse, il s'appuie, bien évidemment sur ses propres travaux ${ }^{(1)}$ ou sur la thèse désormais classique de Nicole Pellegrin, ${ }^{(2)}$ mais surtout sur les masters qu'il a dirigés à l'université de Dijon. JeanClaude Farcy, qui partage ses recherches entre histoire de la justice et histoire rurale du XIXème siècle, ${ }^{(3)}$ croise ses deux champs d'investigation et dresse un panorama des rixes villageoises au XIXème siècle. Jean-Claude Vimont nous propose une " archéologie " du mineur délinquant au XIXème siècle et met en évidence les transformations du regard sur la déviance juvénile qui s'opèrent durant les premières décennies de la République.

Marina Daniel se penche sur les jeunes femmes infanticides au XIXème siècle. Au regard de leur condition sociale, de leur système de défense et de leur traitement judiciaire, les jeunes femmes de Seine-Maritime ne sont guère éloignées des jeunes Bretonnes d'Annick Tillier. ${ }^{(4)}$

Les quartiers correctionnels, sorte de "fantômes du système pénitentiaire ", sont créés à partir de 1868 en lieu et place des colonies correctionnelles prévues à l'article 10 de la loi du 5 août 1850 . Ils fermeront en 1895 après la fondation de la première véritable colonie correctionnelle, celle de Eysses. Christophe Israël étudie la population du quartier correctionnel installé à la prison Bonne
(1) Voir notamment son article bilan « La perception des délinquants en France du XIVème au XIXème siècle ", Revue historique, 1996, n 600, p. 349-363.

(2) Nicole Pellegrin, Les Bachelleries. Organisation et fêtes de la jeunesse dans le Centre-Ouest, XVèmeXVIIIème siècle, Poitiers, Société des antiquaires de l'Ouest, 1982, 400 p.

(3) Voir la recension de son ouvrage sur $L a$ jeunesse rurale dans la France du XIXème siècle dans le $n^{\circ} 7$ de notre revue.

(4) Annick Tillier, Des criminelles au village. Femme infanticides en Bretagne (I825-I865), Rennes, PUR, 2001, 447 p.

Jean-Jacques Yvorel / p. 265 à 266 
Nouvelle de Rouen. Il montre que ce quartier accueille bien peu de véritables criminels mais d'abord les indociles et les révoltés des colonies pénitentiaires. A l'aide des fiches nominatives de recrutement, Mehdi Hussein construit une sociologie des bataillonnaires. Nous devons entendre par là les conscrits dont le casier judiciaire n'est pas sans tache, même s'il s'agit toujours de " petits délits ", et qui sont incorporés dans l'infanterie légère d'Afrique, régiment plus connu sous le nom de Bat' d'af'.

La science médico-psychologique est une grande productrice de catégories. $\mathrm{Au}$ sein de la nosographie de l'avant première guerre mondiale, on trouve " les arriérés anormaux perfectibles » et comme derrière la catégorie se tapit souvent l'institution, le département de la Seine-Inférieure gérera de 1910 à 1960 un établissement dédié à ces " anormaux ". Valérie Cordié nous fait pénétrer dans l'établissement départemental de Grugny mais souligne la difficulté de saisir véritablement " l'évolution des prises en charge ».

Les J3, après les Apaches et avant les Blousons noirs, sont une figure de la dangerosité juvénile. Sophie Victorien s'appuie sur la presse professionnelle et les dossiers des mineurs placés dans un foyer associatif habilité par l'Éducation surveillée pour nous faire mieux connaitre ces jeunes très souvent marqués par la guerre. L'ultime contribution nous introduit au temps présent puisque Gwénola Ricordeau interroge, dans un article stimulant, l'identité du Casseur.

Jean-Jacques Yvorel 